\title{
Synthesis and Characterization of Carbon Nanotubes Reinforced Hydroxyapatite Composite
}

\author{
P. Khalid ${ }^{1,3}$, M. A. Hussain ${ }^{2}$, P. D. Rekha' and A. B. Arun ${ }^{1 *}$ \\ 'Yenepoya Research Centre, Yenepoya University, Mangalore, 575018, India; \\ p.khalid@live.com; rekhapd@hotmail.com; bhagwatharun@hotmail.com \\ 2Department of Electrical and Computer Engineering, King Abdulaziz University, \\ Jeddah, 215895, KSA; abujuveria@gmail.com \\ ${ }^{3}$ Department of Biotechnology, P. A. College of Engineering, VTU, Mangalore, 574153, India
}

\begin{abstract}
Hydroxy Apatite (HA), as a bone mineral component, has been an attractive bioceramic for the reconstruction of hard tissues. However, its poor mechanical properties, including low fracture toughness and tensile strength, have been a significant challenge to the application of HA for the replacement of load-bearing and/or large bone defects.

$0.5 \mathrm{M} \mathrm{Ca}\left(\mathrm{NO}_{3}\right)_{2} \cdot 4 \mathrm{H}_{2} \mathrm{O}$ and $0.5 \mathrm{M}\left(\mathrm{NH}_{4}\right)_{2} \mathrm{HPO}_{4}$ were used to synthesize $\mathrm{HA}$ in situ. Multiwalled Carbon Nanotubes were functionalized by heating at $100^{\circ} \mathrm{C}$ in $3: 1$ ratio of $20 \% \mathrm{H}_{2} \mathrm{SO}_{4}$ and $20 \% \mathrm{HNO}_{3}$ for $60 \mathrm{~m}$ with stirring. Functionalized MWCNTs were dispersed in Sodium Dodecyl Benzene Sulphonate (SDBS) $\left(10 \mathrm{~g} \mathrm{~L}^{-1}\right)$ by sonication.

Hydroxy Apatite (HA) particles were produced in MWCNTs solution by adding $0.5 \mathrm{M} \mathrm{Ca}\left(\mathrm{NO}_{3}\right)_{2} \cdot 4 \mathrm{H}_{2} \mathrm{O}$ and $0.5 \mathrm{M}$ $\left(\mathrm{NH}_{4}\right)_{2} \mathrm{HPO}_{4}$ under vigorously stirring conditions. The composite were dried at $60^{\circ} \mathrm{C}$ followed by washing in distilled water for 3 to 4 times. Heat treatment at $250^{\circ} \mathrm{C}$ was done for $30 \mathrm{~min}$ to obtain CNT-HA powder.

Solution of Polyvinyl Alcohol (PVA) (10 $\left.\mathrm{g} \mathrm{L}^{-1}\right)$ was made by stirring correct quantities of polymer and distilled water at $90^{\circ} \mathrm{C}$ continuously for $2 \mathrm{~h}$. The MWCNT solution in SDBS and MWCNT-HA composite, which has been prepared in advance, was added to the PVA solution and sonicated for $2 \mathrm{~h}$ in a sonic bath followed by subsequently casting, and controlled water evaporation. PVA/MWCNTs and PVA/MWCNTs/HA composite films were obtained by peeling off from the glass plate substrates and kept in a vacuum desiccator until analyzed.

Using FTIR, FESEM, EDS and UTM perform physicochemical characterization of the composite material. FTIR shows the attachments of $\mathrm{PO}_{4}$ and $\mathrm{CO}_{3}$ groups on the composites, which has been further investigated by FESEM and EDS analysis. The EDS results confirmed the presence of the elements such as $\mathrm{Ca}, \mathrm{P}$ and $\mathrm{C}$ in the respective samples. The FESEM confirms HA nanoparticles are densely decorated on MWCNTs. The UTM results shows that overall mechanical properties of the MWCNT-HA composites are significantly improved with increasing concentration of MWCNTs as compared to the PVA film. The organization of CNTs and HA implemented at the nanoscale can further be developed in the form of coatings, nanocomposites, and hybrid powders to enable potential applications in hard tissue reconstruction.
\end{abstract}

Keywords: MWCNTs, Hydroxy Apatite, Nanocomposites, FTIR, FESEM, UTM.

\section{Introduction}

Due to its chemical resemblance to the mineral component of bone, excellent biocompatibility and osteoconductivity [1-3], Hydroxy Apatite (HA) $\left(\mathrm{Ca}_{10}\left(\mathrm{PO}_{4}\right)_{6}\right.$ $\left.(\mathrm{OH})_{2}\right)$ has been widely used for a variety of biomedical applications in dentistry and orthopedics. However, the atypical brittleness and low fracture toughness of HA have restricted its usage in applications such as high load bearing implants [4]. On the other hand, excellent mechanical properties $[5,6]$ and an extremely high Young's Modulus of up to $1 \mathrm{TPa}$ and tensile strength

${ }^{*}$ Corresponding author:

A. B. Arun (bhagwatharun@hotmail.com) 
approaching $63 \mathrm{GPa}[7,8]$, CNTs are considered to be ideal candidates for mechanical reinforcement of polymers [9].

HA is combined with other materials as a second phase in order to improve the mechanical properties of the HA composites. However, significant amounts of the second phase are required for a substantial improvement in the mechanical properties of the composite. Additionally, the bio-inertness or poor bioactivity of these phases often discovered in the HA composite [10]. So, it is necessary to use a second phase with high bioactivity for the fabrication of composite/coatings having good mechanical properties without any deterioration in their bioactivity.

Because of the bioactivity of CNTs [11-13], their use in biomedical applications has been anticipated. The combination of biological and excellent mechanical properties of CNTs has opened a new research field of CNT reinforced HA composite coatings [14, 15]. Plasma Spraying [14], Electrophoretic Deposition [16] and Aerosol Deposition $[17,18]$ are the commonly used methods for CNT-HA coating composites for different biomedical applications.

In the present work, we report a simple method of inclusion of MWCNTs in the HA matrix with the aim of improving biological and mechanical properties of HA. Acid treatment of the pristine MWCNTs and the subsequent ultrasonication processing, allowed good nanotube dispersions at significant high concentration levels. Fabrication of PVA-MWCNT-HA composite film is done using wet-casting method to test Young's Modulus, Tensile Strength and Toughness, etc. Significantly improved overall mechanical properties of these nanocomposite films were observed, as compared to the pure PVA film. Results from mechanical and morphological characterizations of the composite system are presented and discussed.

\section{Experimental Procedure}

\subsection{Materials}

The MWCNTs samples were purchased from Nanoshel LLC, USA. The nanotube has a specified diameter of 20-30 nm. Purity is greater than $95 \%$. Analytical grade of Calcium Nitrate Tetrahydrate $\mathrm{Ca}\left(\mathrm{NO}_{3}\right)_{2} \cdot 4 \mathrm{H}_{2} \mathrm{O}$ and $\mathrm{Di}$-Ammonium Hydrogen Phosphate $\left(\mathrm{NH}_{4}\right)_{2} \mathrm{HPO}_{4}$ were purchased from $\mathrm{Hi}$-media labs with a molecular weight of 164.15 and 132.06 respectively. The polymer matrix
Poly(Vinyl Alcohol) (PVA) which was supplied by Fisher Scientific (85-89\%), was hydrolyzed with an average molecular weight of 88,000 . Ammonia Solution (25\%) was purchased from Merck.

\subsection{In-situ Bio-synthesis of HA}

The HA were synthesized in situ by sol-gel method. $5 \mathrm{ml}$ of $0.5 \mathrm{M} \mathrm{Ca}\left(\mathrm{NO}_{3}\right)_{2} \cdot 4 \mathrm{H}_{2} \mathrm{O}$ is dissolved in distilled water and $\mathrm{pH}$ was adjusted to $\geq 10$. Then $5 \mathrm{ml}$ of absolute ethanol is added to the solution. $10 \mathrm{ml}$ of $0.5 \mathrm{M}\left(\mathrm{NH}_{4}\right)_{2} \mathrm{HPO}_{4}$ is prepared in distilled water and $\mathrm{pH}$ was adjusted to $\geq 10$ and rapidly added to previously prepared $0.5 \mathrm{M}$ $\mathrm{Ca}\left(\mathrm{NO}_{3}\right)_{2} \cdot 4 \mathrm{H}_{2} \mathrm{O}$, under vigorous stirring conditions. $\mathrm{pH}$ of the mixed solutions were kept above or equal to 10 by adding ammonia solution. Stirring was continued for $3 \mathrm{~h}$ followed by aging for $24 \mathrm{~h}$ at room temp. The gel was dried at $60^{\circ} \mathrm{C}$ overnight and repeatedly washed with distilled water followed by heating at $250^{\circ} \mathrm{C}$ in a muffled furnace for 30 minutes to obtain HA powder.

\subsection{Functionalization of MWCNTs}

According to previously published procedure [19], the Multiwalled Carbon Nanotubes $100 \mathrm{mg} / 60 \mathrm{ml}$ were heated at $100^{\circ} \mathrm{C}$ in 3:1 ratio of $20 \% \mathrm{H}_{2} \mathrm{SO}_{4}$ and $20 \% \mathrm{HNO}_{3}$ for $60 \mathrm{~m}$ with stirring. These treated MWCNTs were washed until neutral $\mathrm{pH}$ and dried at $60^{\circ} \mathrm{C}$ [20] for further use.

\subsection{Inclusion of MWCNTs in HA Matrix}

Functionalized MWCNTs $\left(1 \mathrm{~g} \mathrm{~L}^{-1}, 3 \mathrm{~g} \mathrm{~L}^{-1}\right.$ and $\left.5 \mathrm{~g} \mathrm{~L}^{-1}\right)$ were dispersed in Sodium Dodecyl Benzene Sulphonate (SDBS) $\left(10 \mathrm{~g} \mathrm{~L}^{-1}\right)$ by sonication. Hydroxy Apatite (HA) particles were produced in above MWCNTs solution by adding $0.5 \mathrm{M} \mathrm{Ca}\left(\mathrm{NO}_{3}\right)_{2} .4 \mathrm{H}_{2} \mathrm{O}$ and $0.5 \mathrm{M}\left(\mathrm{NH}_{4}\right)_{2} \mathrm{HPO}_{4}$ under vigorous stirring conditions [21]. $\mathrm{pH}$ of the solution were kept above or equal to 10 by adding ammonia solution. Stirring was continuing for $3 \mathrm{~h}$ followed by aging for $24 \mathrm{~h}$ at room temp. The composite were dried at $60^{\circ} \mathrm{C}$ followed by washing in distilled water for 3 to 4 times. Heat treatment at $250^{\circ} \mathrm{C}$ was done for $30 \mathrm{~min}$ to obtain CNT-HA powder.

\subsection{Preparation of PVA Composite Film}

PVA Composite Films with different carbon nanotubes' formulations were fabricated by using the wet-casting method. Solution of PVA $\left(10 \mathrm{~g} \mathrm{~L}^{-1}\right)$ was made by stirring correct quantities of polymer and distilled water at $90^{\circ} \mathrm{C}$ 
continuously for $2 \mathrm{~h}$. Particular amount of the MWCNT solution in SDBS and MWCNT-HA composite, which has been prepared in advance, was added to the PVA solution and sonicated for $2 \mathrm{~h}$ in a sonic bath. Here, sonication was used for crosslinking of MWCNT-HA and PVA. After sonication of aqueous PVA solution with different carbon nanotube formulations followed by subsequently casting, and controlled water evaporation, free-standing PVA/MWCNTs and PVA/MWCNTs/HA composite films were obtained by peeling off from the glass plate substrates and kept in a vacuum desiccator until analyzed.

\section{Physicochemical Characterization}

\subsection{Fourier Transform Infrared Spectroscopy (FTIR)}

Infrared spectra of specimen powders were recorded on a Shimadzu Prestige IR Spectrometer (Shimadzu Prestige 21 series, Japan). Prior to analysis $\mathrm{KBr}$ pellets were prepared by mixing in the ratio of $1: 10$ of sample/ $\mathrm{KBr}(\mathrm{w} / \mathrm{w})$, followed by uniaxially pressing the powder under vacuum. All spectra were obtained between 4000 and 400 $\mathrm{cm}^{-1}$ at a $2 \mathrm{~cm}^{-1}$ resolution.

\subsection{Mechanical Testing}

Tensile tests were carried out on a Lloyd Universal Testing Machine (Model LRX plus). The film samples were cut into strips of $50 \mathrm{~mm} \times 20 \mathrm{~mm} \times 0.11 \mathrm{~mm}$ and fixed on a sample holder and tested at room temperature with the load cell of $5 \mathrm{kN}$ and a gauge length of $30 \mathrm{~mm}$ and crosshead speed of $20 \mathrm{~mm} / \mathrm{min}$. At least three samples were tested for each type of films and then the maximum tensile strength, maximum percentage elongation at break (\%), and elastic modulus (or Young's modulus) were averaged from the 3 measurements.

\subsection{Surface Topography Characterization}

The surface morphology and atomic structure of the HA scaffolds and HA/MWNT scaffolds were examined under the FESEM (Hitachi SU6600, Japan) and EDS (HoribaEMAX). Prior to the microstructure analysis, specimens were coated with gold using an ion sputter coating Instrument (Hitachi E-1010, Japan) with a current set at $15 \mathrm{~mA}$ for a coating time of $15 \mathrm{~s}$.

\section{Result and Discussion}

\subsection{FTIR Analysis}

The Infrared Spectroscopy was used to characterize and understand the molecular vibration/structure of the MWCNT-HA composites; Figure 1 shows the FTIR spectra MWCNT-HA powder. Regarding the FTIR spectrum of the MWCNT-HA composites, it was detected intense absorption bands at 590 and $550 \mathrm{~cm}^{-1}$ and $950-1090 \mathrm{~cm}^{-1}$ which are assigned to phosphate groups with the frequency of vibration $v 4$ and $v 3$, respectively. The bands observed at $3400-3430 \mathrm{~cm}^{-1}$ corresponds to the stretching mode of $-\mathrm{OH}$ group, which is a characteristic of calcium phosphates such as HA [22]. A weak band of $\mathrm{CO}_{3}{ }^{2-}$ was detected in the region around $1450-1700$ and $890 \mathrm{~cm}^{-1}$. The band at $890 \mathrm{~cm}^{-1}$ indicates v2 mode of $\mathrm{CO}_{3}{ }^{2-}$ group $[23,24]$ and it suggests a minor amount of B-type carbonate substitution i.e. small part of the PO4 (B-type) groups in the apatitic structure was replaced by $\mathrm{CO}_{3}$. The characteristic bands from inorganic carbonate ion suggest that carbon gets dissolved in the organics from experimental atmosphere and does not pyrolyze completely and may instead dissolve into the HA crystal. Since carbonates are constituents of bone structures, the presence of $\mathrm{CO}_{3}$ may improve the bioactivity of HA rather than being a cause of concern [25].

\subsection{Mechanical Testing}

Recently, Carbon NanoTubes (CNTs) have been used as reinforcing additive fibers in polymers and metals [26-31]

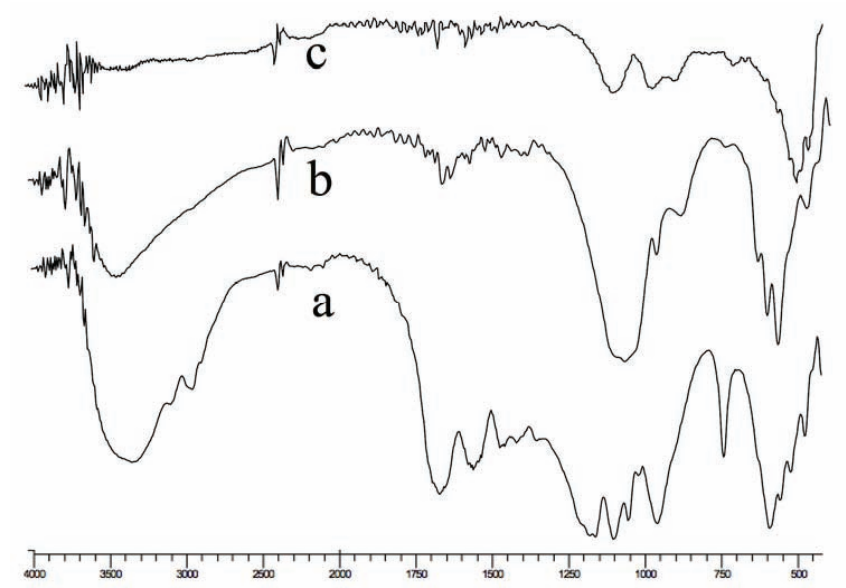

Figure 1. FTIR patterns showing the formation of Hydroxy Apatite (HA) calcined at $250^{\circ} \mathrm{C}$. (a) pure HA; (b) in-situ synthesized HA; (c) MWCNT-HA composites. 
and CNT Reinforced Ceramic Composites [32-38]. The effect of addition of MWCNTs to HA improves the mechanical properties of composites. Table 1. shows the tensile tests in terms of Young's Modulus, strength and toughness of the films corresponding to an average of at least three samples tested for each type of the film. Figure 2 ( $a, b, c, d)$ shows the stress-strain curves for the films containing MWCNTs and MWCNT-HA. Results show that overall mechanical properties of the MWCNT-HA composites are significantly improved with increasing concentration of MWCNTs as compared to the PVA film. The composite film fabricated with MWCNTs-HA shows increased modulus, strength and toughness, which may be ascribed to nucleation of HA around the tubes. The positively charged HA are adsorbed on to the surface of negatively charged MWCNT due to electrostatic attraction and leads to coating of the surface of MWCNTs with HA and ultimately improved mechanical properties of the composite.

\subsection{Surface Topography Characterization}

According to Coulomb's Law, the electrostatic forces are inversely proportional to the dielectric constant of the medium. The electrostatic forces between the ions in HA crystals are higher when organic solvents are used for synthesis. Figure 3 (a,d) shows the functionalized MWCNT's at low and high magnification. Longer interaction between the ions in organic solvents leads to faster reaction and nucleation rate. Hence the smaller particles with regular morphology are synthesized Figure 3 (c, f). These HA nanoparticles are densely decorated on MWCNTs successfully by a simple and effective in situ synthetic method Figure 3 (b, e). The surface modification of MWCNTs by dispersing nanotubes in SDBS solution without degrading the tube surface is effective for imparting a negative charge. The $\mathrm{Ca}^{2+}$ ions then can be adsorbed onto the surface of MWCNTs due to the electrostatic attraction, and in situ react with $\mathrm{PO}^{3-}$ via electrovalent bond to form HA-MWCNT precipitates. The EDS results confirmed the presence of the elements such as $\mathrm{Ca}, \mathrm{P}$ and $\mathrm{C}$ in the respective samples Figure 4. The simple method presented here may be extended to synthesize other composites based on coating MWCNTs with matrix powders by varying type of dispersant.

\section{Conclusions}

MWCNTs-HA-PVA nanocomposites have been prepared with enhanced overall mechanical properties by a simple wetting casting method. Mechanical tests show that, compared with pure PVA, the tensile modulus, the tensile strength and toughness of the composite PVA-MWCNT and PVA-MWCNT-HA are greatly improved. SEM observation of the composite powder indicates that simple

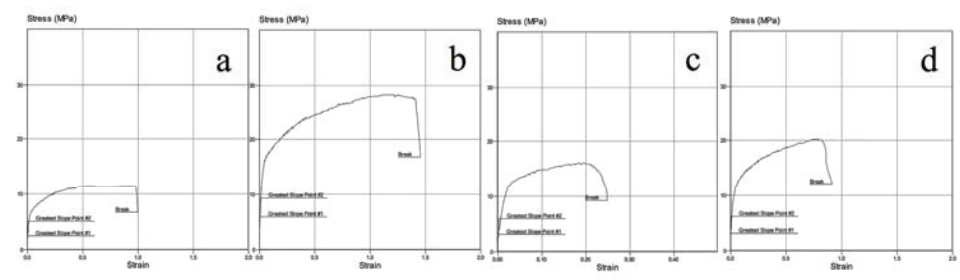

Figure 2. Typical stress-strain curve for a) pure PVA b) PVA-MWCNT c) PVA-MWCNT-HA and d) PVA-HA composites.

Table 1. Summary of mechanical properties of pure PVA and its composite film containing MWCNTs and HA

\begin{tabular}{|c|c|c|c|c|c|c|}
\hline Samples & $\begin{array}{l}\text { Load at } \\
\text { maximum load } \\
(\mathrm{N})\end{array}$ & $\begin{array}{c}\text { Tensile strength } \\
(\mathrm{MPa})\end{array}$ & $\begin{array}{c}\text { Young's } \\
\text { modulus (MPa) }\end{array}$ & $\begin{array}{l}\text { Stress at break } \\
\qquad(\mathrm{MPa})\end{array}$ & $\begin{array}{c}\text { Strain at } \\
\text { break }\end{array}$ & $\begin{array}{c}\text { Percentage total } \\
\text { elongation at } \\
\text { fracture }\end{array}$ \\
\hline PVA & 27.73 & 11.55 & 372.50 & 6.72 & 1.00 & 99.67 \\
\hline $\begin{array}{l}\text { PVA- } \\
\text { MWCNT }\end{array}$ & 44.89 & 28.05 & 579.70 & 16.78 & 1.46 & 145.51 \\
\hline $\begin{array}{l}\text { PVA- } \\
\text { MWCNT- }\end{array}$ & & & & & & \\
\hline $\mathrm{HA}$ & 35.45 & 16.11 & 745.71 & 9.23 & 0.25 & 24.89 \\
\hline PVA-HA & 59.87 & 23.03 & 685.66 & 13.81 & 0.76 & 76.46 \\
\hline
\end{tabular}




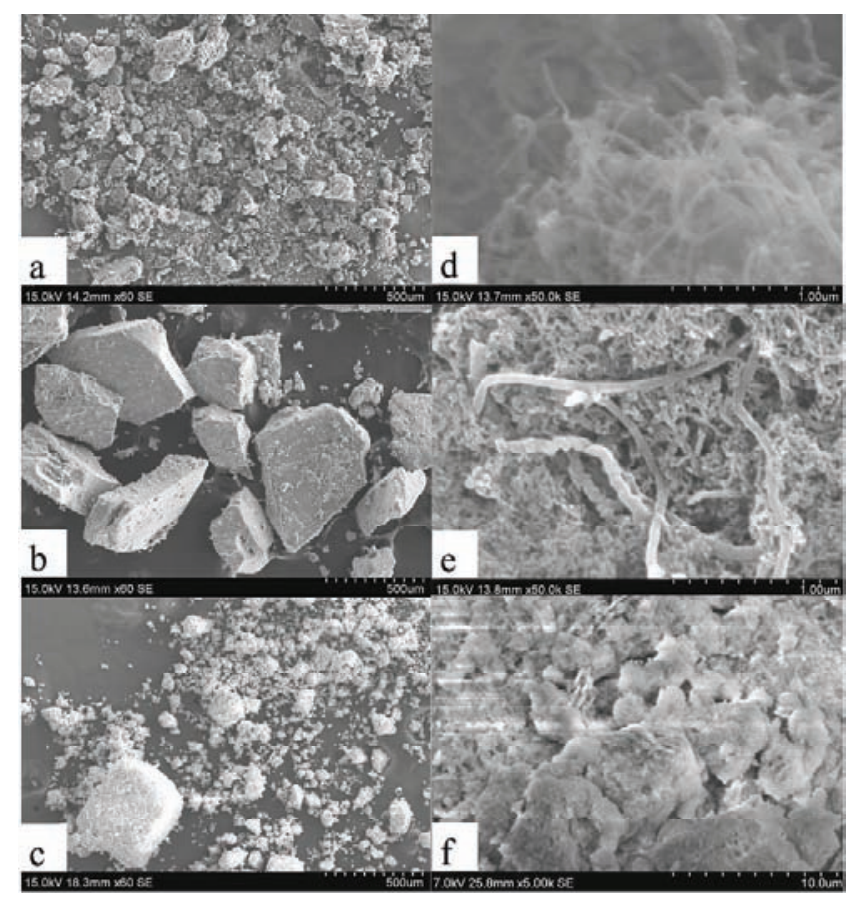

Figure 3. SEM image of (a) functionalized MWCNTs (b) MWCNT-HA composites (c) in-situ synthesized HA powder, at low magnification, (d) functionalized MWCNTs (e) MWCNT-HA composites (f) in-situ synthesized HA powder, at higher magnification at x50k. Comparison of (d) with (e) shows that the sidewall of the tubes was rougher after sintering.



Figure 4. EDS spectrum of (a) functionalized MWCNT (b) MWCNT-HA composites and (c) chemically synthesized HA.

sonication process leads to a homogeneous dispersion of MWNTs throughout HA matrix and a strong interfacial adhesion. These coated nanotubes pave the way for the development of carbon nanotubes composites with a stable tube-matrix interfaces and improved performance when nanotubes are used as fillers in composite materials.

\section{References}

1. Hench L L (1991). Bioceramics: from concept to clinic, Journal of the American Ceramic Society, vol 74(7), 1487-1510.
2. Jarcho M (1981). Calcium phosphate ceramics as hard tissue prosthetics, Clinical Orthopaedics and Related Research, vol 157(6), 259-278.

3. Joshi S V, Srivastava M P et al. (1993). Plasma spraying of biologically derived hydroxyapatite on implantable materials, Journal of Materials Science: Materials in Medicine, vol 4(3), 251-255.

4. With G D, Van Dijk H J A et al. (1981). Preparation, microstructure and mechanical properties of dense polycrystalline hydroxyapatite, Journal of Materials Science, vol 16(6), 1592-1598.

5. Dalton A B, Collins S et al. (2003). Super tough carbonnanotubes fibers, Nature, vol 423(6941), 703.

6. Cadek M, Coleman J N et al. (2002). Morphological and mechanical properties of carbon-nanotube-reinforced semicrystalline and amorphous polymer composites, Applied Physics Letters, vol 81(27), 5123-5125.

7. Frogley M D, Wagner H D et al. (2003). Mechanical properties of carbon nanoparticles reinforced Elastomers, Composites Science and technology, vol 63(11), 1647-1654.

8. Treacy M M J, Ebbesen T W et al. (1996). Exceptionally high young's module observed for individual carbon nanotubes, Nature, vol 381(6584), 678-680.

9. Baughman R H, Zakhidov A A et al. (2002). Carbon nanotubes-the route towards applications, Science, vol 297(5582), 787-792.

10. Gu Y W, Khor K A et al. (2004). Activity of plasma sprayed yttria stabilized zirconia reinforced hydroxyapatite/ Ti-6Al-4V composite coatings in simulated body fluid, Biomaterials, vol 25(16), 3177-3185.

11. Chlopek J, Czajkowska B et al. (2006). In vitro studies of carbon nanotubes biocompatibility, Carbon, vol 44(6), 1106-1111.

12. Zanello L P, Zhao B et al. (2006). Bone cell proliferation on carbon nanotubes, Nano Letters, vol 6(3), 562-567.

13. Usui Y, Aoki K et al. (2008). Carbon nanotubes with high bone-tissue compatibility and bone-formation acceleration effects, Small, vol 4(2), 240-246.

14. Balani K, Anderson R et al. (2007). Plasma-sprayed carbon nanotube reinforced hydroxyapatite coatings and their interaction with human osteoblasts in vitro, Biomaterials, vol 28(4), 618-624.

15. Kaya C, Singh I et al. (2008). Multi-walled carbon nanotube-reinforced hydroxyapatite layers of Ti6Al4V medical implants by Electro Phoretic Deposition (EPD), Advanced Engineering Materials, 10(1-2), 131-138.

16. Wei M, Ruys A J et al. (2005). Precipitation of hydroxyapatite nanoparticles: effects of precipitation method on electrophoretic deposition, Journal of Materials Science: Materials in Medicine, vol 16(4), 319-324.

17. Hahn B D, Park D S et al. (2008). Effects of Zr/Ti ratio and post-annealing temperature on the electrical properties of 
PZT thick films fabricated by aerosol deposition, Journal of Materials Research, vol 23(1), 226-235.

18. Hahn B D, Kim K H et al. (2008). Fabrication of lead zirconate titanate thick films using a powder containing organic residue, Japanese Journal of Applied Physics, vol 47(7), 5545-5552.

19. Khalid P, Hussain M A et al. (2013). Modifications of carbon nanotubes for bioapplication and toxicity evaluations, Journal of Environmental Nanotechnology, vol 2(1), 70-74.

20. Yao W, Jun W et al. (2003). A treatment method to give separated multi walled carbon nanotubes with high purity, high crystallization and large aspect ratio, Carbon, vol 41(15), 2939-2948.

21. Najafi H, Nemati Z A et al. (2009). Inclusion of carbon nanotubes in a hydroxyapatite sol-gel matrix, Ceramics International, vol 35(7), 2987-2991.

22. Raynaud S, Champion E et al. (2002). Calcium phosphate with variable $\mathrm{Ca} / \mathrm{P}$ atomic ratio. I. synthesis, characterization and thermal stability of powders, Biomaterials, vol 23(4), 1065-1072.

23. Elliott J C (1994). Structure and chemistry of the apatites and other calcium orthophosphates, 2nd Edn., Chapter 2, Elsevier, Amsterdam.

24. Emerson W H, and Fischer E E (1962). The infra-red absorption spectra of carbonate in calcified tissues, Archives of Oral Biology, vol 7(6), 671-683.

25. Rajabi-Zamani A H, Behnamghader A et al. (2008). Synthesis of nanocrystaline carbonated hydroxyapatite powder via nanoalkoxide sol-gel method, Materials Science and Engineering C, vol 28(8), 1326-1329.

26. Grunlun J C, Mehrabi A R et al. (2004). Water based single walled nanotube filled polymer composite with an exceptionally low percolation threshold, Advanced Materials, vol 16(2), 150-153.

27. Sen R, Zhao B et al. (2004). Preparation of single-walled carbon nanotube reinforced polystyrene and polyurethane nano-fibers and membranes by electrospinning, Nano Letters, vol 4(3), 459-464.
28. Huang J, Li X et al. (2003). Well-dispersed single-walled carbon nanotube/polyaniline composite films, Carbon, vol 41(14), 2731-36.

29. Kuzumaki T (2000). Mechanical characteristics and preparation of carbon nanotubes fiber-reinforced $\mathrm{Ti}$ composite, Advanced Engineering Materials, vol 2(7), 416-418.

30. Laha T, Kuchibhatla $S$ et al. (2007). Interfacial phenomena in thermally sprayed multiwalled carbon nanotube reinforced aluminum nanocomposite, Acta Materialia, vol 55(3), 1059-1066.

31. Deng C F, Wang D Z et al. (2007). Damping characteristics of carbon nanotube reinforced aluminum composite, Materials Letters, vol 61(14-15), 3229-3231.

32. Peigney A, Laurent $\mathrm{Ch}$ et al. (2000). Carbon nanotubes in novel ceramic matrix nanocomposites, Ceramics International, vol 26(6), 677-83.

33. Balazsi Cs, Konya $Z$ et al. (2003). Preparation and characterization of carbon nanotube reinforced silicon nitride composites, Materials Science and Engineering C, vol 23(6-8), 1133-1137.

34. Lupo F, Kamalakaran R et al. (2004). Microstructural investigations on zirconium oxide-carbon nanotube composites synthesized by hydrothermal crystallization, Carbon, vol 42(10), 1995- 1999.

35. Rul S, Lefevreschlick F et al. (2004). Percolation of single-walled carbon nanotubes in ceramic matrix nanocomposites, Acta Materialia, vol 52(4), 1061-1067.

36. Xia Z, Riester L et al. (2004). Direct observation of toughening mechanisms in carbon nanotube ceramic matrix composites, Acta Materialia, vol 52(4), 931-944.

37. Wang Y, Iqbal $Z$ et al. (2006). Rapid, low temperature microwave synthesis of novel carbon nanotube-silicon carbide composite, Carbon, vol 44(13), 2804-2808.

38. Wang J, Kou H et al. (2007). Reinforcement of mullite matrix with multi-walled carbon nanotubes, Ceramics International, vol 33(5), 719-722. 